BMJ Paediatrics Open

\section{Rare disease: a national survey of paediatricians' experiences and needs}

To cite: Zurynski Y, Gonzalez A, Deverell M, et al. Rare disease: a national survey of paediatricians' experiences and needs. BMJ Paediatrics Open 2017;1:e00172. doi:10.1136/ bmjpo-2017-000172

- Additional material is published online only. To view please visit the journal online (http://dx.doi.org/10.1136/ bmjpo-2017-000172)

Received 27 June 2017 Revised 4 September 2017 Accepted 5 September 2017

\section{(a) CrossMark}

For numbered affiliations see end of article.

\section{Correspondence to}

Dr Yvonne Zurynski, Australian Paediatric Surveillance Unit, Kids Research Institute, Westmead, NSW 2145, Australia; yvonne. zurynski@health.nsw.gov.au

\section{ABSTRACT}

Objective To describe the experiences of Australian paediatricians while caring for children with rare diseases, and their educational and resource needs.

Design A brief online survey was developed and deployed to a representative sample of 679 paediatricians from the Australian Paediatric Surveillance Unit database.

Results Of the 679 paediatricians, 242 (36\%) completed the survey. The respondents were representative of all states and territories of Australia, urban and rural regions, and hospital and private practice. Almost all respondents $(93 \%)$ had seen children with one or more of $>350$ different rare diseases during their career; $74 \%$ had seen a new patient with rare disease in the last 6 months. The most common problems encountered while caring for patients were: diagnostic delays (65\%), lack of available treatments (40\%), clinical guidelines (36\%) and uncertainty where to refer for peer support $(35 \%)$. Few paediatricians said that rare diseases were adequately covered during university (40\%) or the Fellowship of the Royal Australasian College of Physicians (50\%) training, and 28\% felt unprepared to care for patients with rare diseases. Paediatricians wanted lists of specialist referral services $(82 \%)$ and online educational modules about rare diseases (78\%) that could be accessed via one online portal that consolidated multiple resources. Smartphone applications on rare diseases were favoured by paediatricians aged $<50$ years and by female paediatricians.

Conclusions An online educational portal should be developed and maintained for accuracy and currency of information to support dissemination of rare disease guidelines, referral pathways and coordination services relevant to Australian paediatricians and other health professionals who care for children with rare diseases.

\section{INTRODUCTION}

Specialist paediatricians play a pivotal role in identifying, diagnosing and treating children with rare diseases. ${ }^{1}$ Collectively, rare diseases are common, with approximately 8000 known rare diseases mostly with onset in childhood. ${ }^{1-3}$ Children living with rare diseases often require specialist care from large teams of health professionals because of disease complexity and associated intellectual and physical disability.

\section{What is already known on this topic?}

Parents of children living with rare diseases report that doctors lack knowledge about rare diseases.

- Diagnostic delays are common in children with rare diseases.

- There have been no studies of the needs of paediatricians who care for children with rare diseases.

\section{What this paper adds?}

A study of paediatricians' knowledge, attitudes, practice and educational needs regarding rare childhood diseases.

- Paediatricians commonly see children with rare diseases but report difficulties including reaching a definitive diagnosis, lack of available treatments and guidelines, and uncertain referral pathways.

- Paediatricians called for better education about rare diseases, including a one-stop online hub where evidence-based resources could be deposited and accessed.

Patients with rare diseases often face lengthy diagnostic delays, some families seeing between 3 and 10 different doctors and waiting $>5$ years for a definitive diagnosis. ${ }^{4-6}$ We found that approximately $30 \%$ of Australian families who experienced diagnostic delays attribute delays to lack of health professionals' knowledge and difficulties accessing specialised genetic testing within a reasonable time frame. ${ }^{45}$ Delayed diagnosis limits access to early intervention programme, could delay appropriate treatment and might result in patients receiving the wrong treatment. ${ }^{57}$

The burden of rare diseases on tertiary paediatric hospitals is significant. ${ }^{4-10}$ Their complexity and chronicity means that children need ongoing multidisciplinary care from paediatric specialists, allied health professionals and disability services. Furthermore, paediatric generalists often provide 
routine care, review children between visits to specialist clinics, coordinate care and organise appropriate referrals. ${ }^{1112}$ General paediatricians in rural Australia, where health services are limited, may experience problems when managing children with rare diseases, including obtaining specialist advice and accessing genetic testing and imaging technologies. ${ }^{13}$

To our knowledge there is only one report about the experiences of doctors while caring for patients with rare diseases. ${ }^{14}$ That report, published by a pharmaceutical company, included a sample of 50 physicians (4 paediatricians) in the USA and 50 physicians in the UK (25 paediatricians). ${ }^{14}$ It is unlikely to be representative given the small sample sizes and a lack of description of how physicians were selected and recruited. ${ }^{14}$

Our study aims to describe paediatricians' clinical practice regarding rare diseases, the difficulties they encounter, their information-seeking behaviours and their educational needs and preferences. Such information is needed to inform clinical guidelines, educational initiatives and new models of healthcare for children with rare diseases.

\section{METHODS}

\section{Survey development}

We developed a brief survey for paediatricians which asked about the following:

- gender, age, state/territory and postcode of practice, year of attainment of the Fellowship of the Royal Australasian College of Physicians (FRACP) or equivalent;

- practice setting (hospital/private practice), practice type (general or subspecialty paediatrics, remoteness (metropolitan, rural, remote) $;^{15}$

- clinical experience with rare disease patients;

- difficulties encountered when looking after children with rare diseases;

- education received about rare diseases;

- current use of information resources in clinical practice;

- preferred mode of delivery for educational resources (face-to-face, printed materials, online modules).

The survey included structured response questions with multiple tick options and Likert rating scales. Free-text answers were collected for questions about difficulties encountered when diagnosing or managing patients with rare diseases. The draft survey was reviewed for relevance by all authors and leaders of parent/peer support organisations including Genetic Alliance Australia, formerly the Association of Genetic Support of Australasia (AGSA); the Steve Waugh Foundation and SMILE Foundation (now Variety, The Children's Charity). A convenience sample of 10 paediatricians trialled the survey and provided feedback about relevance, clarity, gaps and redundancies of questions, and survey length. All feedback was incorporated into the final version (online Supplementary file) and an e-survey form was developed using the Research Electronic Data Capture Software (REDCap). ${ }^{16}$

\section{Participants}

In March 2015, the survey was sent to 679 paediatricians selected from the Australian Paediatric Surveillance Unit (APSU) database, which included 1366 paediatricians at that time. APSU recruits Fellows in Paediatrics and Child Health of the Royal Australasian College of Physicians (FRACP) as they graduate, whether or not they

\begin{tabular}{|c|c|c|}
\hline Variable & & $\mathbf{N}(\%)$ \\
\hline \multirow[t]{2}{*}{ Gender } & Man & $116(48)$ \\
\hline & Woman & $126(52)$ \\
\hline \multirow[t]{2}{*}{ Age groups } & $\leq 50$ & $137(57)$ \\
\hline & $>50$ & $104(43)$ \\
\hline \multirow{3}{*}{$\begin{array}{l}\text { Year of FRACP award } \\
\text { or equivalent }\end{array}$} & Pre 1980 & $9(4)$ \\
\hline & 1980-1999 & 94 (39) \\
\hline & $\geq 2000$ & $138(57)$ \\
\hline \multirow[t]{8}{*}{ State of practice } & New South Wales & $85(35)$ \\
\hline & Victoria & $65(27)$ \\
\hline & Queensland & $40(17)$ \\
\hline & Western Australia & $25(10)$ \\
\hline & South Australia & $11(5)$ \\
\hline & ACT & $8(3)$ \\
\hline & Tasmania & $3(1)$ \\
\hline & Northern territory & $2(1)$ \\
\hline \multirow{3}{*}{$\begin{array}{l}\text { ASGC postcode } \\
\text { classification of } \\
\text { remoteness }\end{array}$} & Metropolitan (RA 1) & $205(85)$ \\
\hline & Rural (RA 2-3) & 32 (13) \\
\hline & Remote (RA 4-5) & $2(1)$ \\
\hline \multirow[t]{2}{*}{ Specialty } & Paediatric generalist & $130(54)$ \\
\hline & Subspecialist & $111(46)$ \\
\hline \multirow[t]{3}{*}{ Practice type } & Hospital-based & $135(56)$ \\
\hline & Private practice & $19(8)$ \\
\hline & $\begin{array}{l}\text { Hospital and private } \\
\text { practice }\end{array}$ & $85(35)$ \\
\hline \multirow{5}{*}{$\begin{array}{l}\text { Number of new } \\
\text { patients seen in a } \\
\text { typical week }\end{array}$} & $<1$ & $4(2)$ \\
\hline & $1-5$ & 79 (33) \\
\hline & $5-10$ & $92(38)$ \\
\hline & $10-20$ & 46 (19) \\
\hline & $>20$ & $19(8)$ \\
\hline \multirow{5}{*}{$\begin{array}{l}\text { Number of rare } \\
\text { disease patients seen } \\
\text { during clinical career }\end{array}$} & $1-5$ & $22(10)$ \\
\hline & $6-10$ & 35 (16) \\
\hline & $11-20$ & $29(13)$ \\
\hline & $>20$ & $69(31)$ \\
\hline & $>100$ & $66(30)$ \\
\hline
\end{tabular}

ASGC, Australian Standrad Geographical Classification; FRACP, Fellowship of the Royal Australasian College of Physicians. 
Table 2 Rare disease categories seen most frequently by paediatricians during their career

\begin{tabular}{|c|c|c|}
\hline Type of rare disease & $\mathbf{N}(\%)$ & Examples of specific diseases \\
\hline Metabolic/genetic & $198(88)$ & $\begin{array}{l}\text { Galactosaemia; medium-chain acyl-CoA dehydrogenase deficiency; phenylketonuria; } \\
\text { citrullaemia; ornithine transcarbamylase deficiency; trisomies } 8,13,18\end{array}$ \\
\hline Immunological & $102(45)$ & $\begin{array}{l}\text { Severe combined immunodeficiency; IgA deficiency; hyper IgE syndrome; chronic } \\
\text { granulomatous disease }\end{array}$ \\
\hline Skeletal & $95(42)$ & Achondroplasia; osteogenesis imperfecta; osteopetrosis; asphyxiating thoracic dystrophy \\
\hline Respiratory & $80(36)$ & Alveolar capillary dysplasia; pulmonary lymphangiectasis; surfactant protein C deficiency \\
\hline Endocrine & $80(36)$ & $\begin{array}{l}\text { Congenital hypothyroidism; McCune-Albright } \\
\text { syndrome; hypophosphatasia; congenital adrenal hyperplasia }\end{array}$ \\
\hline Gastrointestinal & $77(34)$ & $\begin{array}{l}\text { Biliary atresia; giant omphalocoele; gut duplication; } \\
\text { Neonatal haemochromatosis; Crohn's disease }\end{array}$ \\
\hline Dermatological & $75(33)$ & $\begin{array}{l}\text { Epidermolysis bullosa; incontinentia pigmenti; Stevens-Johnson syndrome; toxic epidermal } \\
\text { necrolysis }\end{array}$ \\
\hline Connective tissue & $73(32)$ & $\begin{array}{l}\text { Pseudoxanthoma elasticum; Marfan syndrome; } \\
\text { Ehlers-Danlos syndrome }\end{array}$ \\
\hline Cancer & $71(32)$ & $\begin{array}{l}\text { Medulloblastoma; Wilms; retinoblastoma; atypical teratoid rhabdoid tumour; Ewing's } \\
\text { sarcoma; hepatoblastoma; childhood melanoma }\end{array}$ \\
\hline Infectious & 52 (23) & $\begin{array}{l}\text { Kingella kingae infection; HIV infection; onchocerciasis; } \\
\text { respiratory papillomatosis }\end{array}$ \\
\hline Rheumatic & $39(17)$ & Juvenile onset rheumatoid arthritis; systemic lupus erythematosus; Behçet's disease \\
\hline
\end{tabular}

CoA, coenzyme A.

have an interest in rare diseases. About $54 \%$ are general paediatricians, and the rest are paediatric subspecialists (emergency physicians, endocrinologists, neonatologists, geneticists and so on) paediatric surgeons and child psychiatrists. ${ }^{1718}$

In this paper we refer to all respondents as paediatricians. To obtain a representative sample, the APSU list was stratified by state/territory jurisdiction, ordered alphabetically within each state/territory and every second paediatrician was selected to participate. The 10 paediatricians who piloted the survey were excluded.

\section{Procedure}

An email containing a personalised web link to the survey was sent. No identifying information was collected apart from the paediatrician's APSU ID number, which was used to track responses. Reminder emails were sent to non-responders 2 and 4 weeks after the initial email.

\section{Data analysis}

Data were exported from REDCap into the Statistical Package for Social Science (IBM SPSS) and analysed using descriptive statistics: mean, SD, frequencies and percentages. For non-parametric variables, median and IQR was calculated. Associations between groups were tested using the $\mathrm{X}^{2}$ test.

\section{Ethics approval}

Ethics approval and research governance approval were obtained from the Sydney Children's Hospitals Network Human Research Ethics Committee (LNR/14/ SCHN/496; LNRSSA/14/SCHN/505).

\section{RESULTS}

Demographics and clinical experience with rare diseases Of paediatricians surveyed 242 (36\%), completed the survey, with representation from all states/territories (table 1). There were $52 \%$ women, $57 \%$ were $<51$ years old, $57 \%$ received their FRACP in 2000 or later and over a half $(54 \%)$ were general paediatricians (table 1$)$. The majority $(85 \%)$ practised in a metropolitan area, and $56 \%$ in a hospital setting (table 1 ). There was no significant difference between responders and non-responders on state/territory or specialty. The demographic details of the responders match with previously published APSU data. ${ }^{18}$ Almost all $(98 \%)$ had reliable internet access. Interestingly, the three with unreliable internet access were based in a metropolitan centre. There was little difference in the use of smartphones and computer tablets in everyday clinical practice between paediatricians based in rural or remote regions $(79 \%)$ and metropolitan settings $(74 \%)$. 
Table 3 Difficulties encountered by paediatricians while caring for children with rare diseases

\begin{tabular}{ll}
\hline Areas of difficulty & $\mathbf{n = 2 3 8 ( \% )}$ \\
\hline $\begin{array}{l}\text { Delay in, or inability to make a definitive } \\
\text { diagnosis }\end{array}$ & $155(65)$ \\
\hline Lack of available treatments & $94(40)$ \\
$\begin{array}{l}\text { Lack of treatment/management guidelines } \\
\text { Lack of diagnostic guidelines }\end{array}$ & $86(36)$ \\
$\begin{array}{l}\text { Uncertainty about available peer support } \\
\text { groups for the patient and family }\end{array}$ & $83(35)$ \\
\hline Lack of access to diagnostic tests & $73(31)$ \\
$\begin{array}{l}\text { Difficulties in accessing specialised clinics/ } \\
\text { services }\end{array}$ & $68(29)$ \\
$\begin{array}{l}\text { Difficulties in accessing genetic testing/ } \\
\text { services }\end{array}$ & $65(27)$ \\
\hline $\begin{array}{l}\text { Difficulties in accessing allied health services } \\
\text { Uncertainty about where to refer to }\end{array}$ & $62(26)$ \\
\hline $\begin{array}{l}\text { Difficulty accessing new drugs or therapies } \\
\text { currently available overseas, not yet licensed } \\
\text { in Australia }\end{array}$ & $49(21)$ \\
\hline \begin{tabular}{l} 
Other difficulties \\
\hline
\end{tabular} & $14(6)$ \\
\hline
\end{tabular}

Most $(89 \%)$ of respondents believed that $\leq 5 \%$ of the child population has a rare disease. Most (71\%) respondents saw $1-10,19 \%$ saw $10-20$, and $8 \%$ saw $>20$ new patients per week (table 1). Almost all respondents $(93 \%)$ had seen at least one child with a rare disease during their clinical career. About two-thirds $(60 \%)$ had seen $>20$ such children during their career (table 1) and most of these were paediatric subspecialists including geneticists, neonatologists, neurologists or surgeons. Over 350 different rare diseases were seen (table 2). Paediatricians who had seen $>100$ rare disease patients in their clinical career were more likely to have completed their FRACP before $2000\left(\chi^{2}=4.66 ; p=0.03\right)$. The majority of respondents $(97 \%)$ reported caring for children with undiagnosed clusters of signs and symptoms, with $57 \%$ seeing $\geq 10$ such patients during their clinical career. In total, 238 (98\%) clinicians had seen children with rare diseases and/or undiagnosed clusters of signs and symptoms, and of these, $97 \%$ had seen a new case in the last 3 years and $74 \%$ had seen a new case in the last 6 months.

Almost all paediatricians (98\%) reported encountering at least one difficulty when caring for children with rare diseases, most commonly delays in reaching a definitive diagnosis, lack of available treatments, lack of clinical guidelines, uncertainty about existence of peer support groups for patients and parents and lack of access to diagnostic tests (table 3). Other difficulties included accessing allied health services, uncertainties about referral pathways, accessing genetic testing and accessing drugs currently available overseas, but not licensed in Australia (table 3).
Confidence about ability to care for children with rare diseases

Almost all (99\%) paediatricians acknowledged rare diseases are important, $72 \%$ felt prepared to look after these patients, and $62 \%$ were confident about where to find information about rare diseases. Most paediatricians $(92 \%)$ said that they would use a directory of specialist services if one was available, and $64 \%$ were confident about referral pathways. The majority $(87 \%)$ believed that patients with rare disease are best looked after in a multidisciplinary clinic and $79 \%$ said they had adequate access to rare disease experts.

\section{Awareness and use of educational resources}

Less than half $(40 \%)$ of paediatricians said rare diseases were adequately covered in their medical degree, while $50 \%$ said they were adequately covered during FRACP training. Paediatricians reported using the following sources of information in everyday clinical practice: consultation with colleagues (92\%); web-based resources $(91 \%)$; textbooks $(49 \%)$ and mobile phone or tablet applications (apps) (30\%).

All respondents were aware of Medline (100\%), and almost all were aware of the Cochrane Library, Up-To-Date and National Institutes for Healthcare Excellence (NICE) guidelines (table 4). Few respondents were aware of rare disease resources. The best known included APSU protocols, case definitions and website, Online Mendelian Inheritance in Man, Pictures Of Standard Syndromes and Undiagnosed Malformations and the portal for rare diseases and orphan drugs (Orphanet) (table 4). Just over $40 \%$ of respondents had attended lectures or workshops on rare diseases in the last 5 years, and most found these useful in terms of content $(93 \%)$, resources $(61 \%)$ and networking opportunities (59\%) (table 4).

\section{Paediatricians' needs for education and resources to support} practice

Respondents favoured web portals providing fact sheets, lists of peer support groups for patients and lists of specialist services for referral (table 5). Three-quarters indicated they would use educational modules about rare diseases if offered via the APSU or RACP websites. Smartphone/tablet apps supporting rare disease diagnosis and management were favoured by $72 \%$ (table 5 ). Paediatricians aged $\leq 50$ years were significantly more likely to access smartphone/tablet apps on rare disease diagnosis and clinical management $\left(X^{2}=13.5 ; p<0.001\right)$, as were female paediatricians $\left(\mathrm{X}^{2}=6.9 ; \mathrm{p}<0.01\right)$.

Factors that would increase the use of information resources included up to date clinically relevant content (97\%), access through a single web portal $(93 \%)$ and free or low cost $(93 \%)$.

\section{DISCUSSION}

This is the first study of paediatricians' experiences of providing care to patients with rare diseases using a 
Table 4 Awareness and usefulness of rare disease internet resources

\begin{tabular}{|c|c|c|c|c|}
\hline Internet resource & $\mathbf{N}^{*}$ & $\begin{array}{l}\text { Aware of } \\
\text { resource } \mathrm{N}(\%)\end{array}$ & $\begin{array}{l}\text { Aware and used } \\
\text { resource } \mathrm{N}(\%)\end{array}$ & $\begin{array}{l}\text { Aware, used and } \\
\text { found resource } \\
\text { useful } N(\%)\end{array}$ \\
\hline \multicolumn{5}{|l|}{ Rare disease-specific resources } \\
\hline $\begin{array}{l}\text { APSU Study protocols, case definitions, website } \\
\text { and report }\end{array}$ & 239 & $213(90)$ & $128(54)$ & $50(21)$ \\
\hline OMIM & 234 & $178(76)$ & $118(50)$ & $73(31)$ \\
\hline POSSUM & 233 & $157(67)$ & $64(28)$ & $30(13)$ \\
\hline Orphanet Portal for Rare Diseases & 234 & $116(50)$ & $66(28)$ & 45 (19) \\
\hline Orphanet Journal of Rare Diseases & 231 & $92(40)$ & $43(19)$ & $26(11)$ \\
\hline HGSA & 226 & 89 (39) & $25(11)$ & $9(4)$ \\
\hline NORD, USA & 235 & $83(35)$ & $26(11)$ & $13(6)$ \\
\hline AGSA† & 225 & $50(22)$ & $15(7)$ & $7(3)$ \\
\hline Centre for Genetic Education (NSW Health) & 227 & $49(22)$ & $28(12)$ & $20(9)$ \\
\hline EURORDIS & 228 & $47(21)$ & $15(7)$ & $5(2)$ \\
\hline \multicolumn{5}{|l|}{ General resources } \\
\hline PubMed, Medline, or similar & 240 & $240(100)$ & $235(98)$ & $168(71)$ \\
\hline Cochrane Library & 234 & $233(100)$ & $208(89)$ & $127(61)$ \\
\hline Up-To-Date & 239 & $233(98)$ & $203(85)$ & $147(72)$ \\
\hline BMJ Best Practice guidelines & 237 & $216(91)$ & $136(57)$ & $62(46)$ \\
\hline NICE, UK & 236 & $222(94)$ & $182(77)$ & $117(64)$ \\
\hline RACP website and CME Resources & 231 & $199(87)$ & $107(46)$ & $23(22)$ \\
\hline $\begin{array}{l}\text { Centres for Disease Control National Guidelines } \\
\text { Clearing House }\end{array}$ & 235 & $120(51)$ & $49(21)$ & $18(37)$ \\
\hline
\end{tabular}

*Number of respondents that answered this question.

†AGSA changed its name to Genetic Alliance Australia.

AGSA, Association of Genetic Support of Australasia; EURORDIS; CME, continuing medical education; European Organisation for Rare Diseases; HGSA, Human Genetics Society of Australia; NICE, National Institutes for Health and Clinical Excellence; NORD, National Organisation for Rare Diseases; OMIM, Online Mendelian Inheritance in Man; POSSUM, Pictures Of Standard Syndromes and Undiagnosed Malformations; RACP, Royal Australasian College of Physicians.

representative, systematically recruited sample $(n=242)$. Almost all $(98 \%)$ of paediatricians in our survey had encountered patients with rare diseases or unusual undiagnosed syndromes in their clinical career. Approximately one-third had seen $\geq 100$ diagnosed cases representing a wide variety of conditions. Almost three-quarters saw a new case in the last 6 months. Our results align with the reported high economic burden of genetic disorders in a population-based study in Western Australia. ${ }^{8}$

Paediatricians experienced problems when caring for children with rare diseases, most commonly delay or inability to make a definitive diagnosis. This was attributed to difficulties accessing diagnostic tests including genetic tests. In Australia, the number of tests covered by the publicly funded Medicare Benefits Scheme has remained static but new tests have become available, many of which are not covered, leading to potential inequitable access to genetic testing according to the individual's financial situation. ${ }^{19}$ Similar concerns about access to genetic tests have been reported by patients' families. ${ }^{56}$ Paediatricians also reported delays in interpretation of genetic tests, suggesting a need for increased clinical genetics capacity in Australia. The burden on clinical geneticists will undoubtedly increase with availability of cheaper sequencing, however delays in clinical interpretation of variants and diagnostic delays should ultimately diminish. ${ }^{20}$

The lack of clinical guidelines, lack of treatment options and inability to access drugs that there are available overseas but not licensed in Australia also frustrates paediatricians. Paediatricians reported difficulties in accessing allied health services and uncertainties about referral pathways. Parents also report problems in accessing treatments, allied health services and care coordination. ${ }^{4-6}$

A report by the pharmaceutical company Shire involving 50 physicians from the USA and 50 from UK showed that they needed to see rare disease patients more frequently than other patients for diagnosis and monitoring and found coordinating their care difficult. ${ }^{14}$ This concurs with our studies of paediatricians and parents. ${ }^{4-6}$ A large proportion of physicians in the Shire report (USA $86 \%$; UK $90 \%$ ) reported difficulties accessing treatments, compared with only $40 \%$ in our study. This stark difference is not easily explained given that more rare drugs 
Table 5 Likelihood of paediatricians using different types of educational resources, if they were available

\begin{tabular}{llll}
\hline Type of resource & $\mathbf{N}^{*}$ & Likely to use N (\%) & $\begin{array}{l}\text { Unlikely to use N } \\
\text { (\%) }\end{array}$ \\
\hline $\begin{array}{l}\text { A web portal providing fact sheets about specific rare diseases which you } \\
\text { could give to your patients }\end{array}$ & 239 & $11(5)$ \\
\hline $\begin{array}{l}\text { A web portal providing a listing of support groups available for your } \\
\text { patients and their families }\end{array}$ & 238 & $222(93)$ & $16(7)$ \\
$\begin{array}{l}\text { A web portal providing a listing of specialists and specialist clinics you } \\
\text { can refer your patients to }\end{array}$ & 238 & $196(82)$ & $42(18)$ \\
$\begin{array}{l}\text { Online modules via the APSU or RACP about specific rare diseases or } \\
\text { groups of rare diseases }\end{array}$ & 240 & $188(78)$ & $52(22)$ \\
$\begin{array}{l}\text { Online modules via the APSU or RACP about how to use already existing } \\
\text { online resources }\end{array}$ & 237 & $166(70)$ & $71(30)$ \\
\hline $\begin{array}{l}\text { Smartphone/tablet applications on rare disease diagnosis and } \\
\text { management }\end{array}$ & 232 & $166(72)$ & $66(28)$ \\
\hline $\begin{array}{l}\text { Printed materials/modules about specific rare diseases or groups of rare } \\
\text { diseases }\end{array}$ & 234 & $160(68)$ & $74(32)$ \\
\hline $\begin{array}{l}\text { Smartphone/tablet applications about how to use already existing online } \\
\text { resources }\end{array}$ & 233 & $153(66)$ & $80(34)$ \\
\hline $\begin{array}{l}\text { Face-to-face educational workshops/seminars about specific rare } \\
\text { diseases or groups of rare diseases }\end{array}$ & 235 & $149(63)$ \\
\hline $\begin{array}{l}\text { Face-to-face educational workshops/seminars about how to use already } \\
\text { existing on-line resources }\end{array}$ & 237 & $122(51)$ & $86(37)$ \\
\hline
\end{tabular}

*Number of respondents that answered this question.

APSU, Australian Paediatric Surveillance Unit; RACP, Royal Australasian College of Physicians.

are licensed in the USA and UK than in Australia. The Shire report had a small sample and did not describe the selection, recruitment and representativeness of the respondents, making comparisons difficult. ${ }^{14}$

Our study is the first to highlight paediatricians' awareness and use of educational resources, specifically when caring for patients with rare diseases. Only $57 \%$ said their medical degree prepared them to recognise patients with rare diseases and one-third felt 'unprepared' to care for children with rare diseases. The French National Plan for Rare Diseases stipulates that the undergraduate medical curriculum must include specific education in rare diseases, including how to access reliable information. ${ }^{21}$ There is no such requirement in Australia, and almost $40 \%$ of respondents in our study lacked confidence about finding reliable information about rare diseases.

The majority were aware of, and used online educational resources including Medline, the Cochrane Library, and the NICE guidelines to support their clinical practice. Fewer were aware of, or had used, rare disease specific resources such as OMIM, POSSUM and the Orphanet portal. Only $35 \%$ were aware of the NORD portal, which houses 'Physician Guides' for over 1200 rare diseases ${ }^{22}$ and only $22 \%$ were aware of the New South Wales Health Centre for Genetics Education. ${ }^{23}$

Almost 90\% were aware of APSU resources on rare diseases for example, case definitions, surveillance protocols and reports and just over half had used these resources. This high level of awareness of APSU resources was likely biased as the sample was drawn from the APSU.
The relatively low use of APSU resources may depend on the paediatrician seeing a child with one of the 60 rare conditions for which APSU provides resources. APSU plans to extend the reach and usefulness of these resources for clinicians.

The APSU database was estimated to represent $\sim 90 \%$ of Australian paediatricians in active clinical practice. ${ }^{17} 18$ The relatively small response fraction and the likelihood of response from paediatricians who are interested in, or have exposure to patients with rare diseases, might have introduced some bias. Nevertheless the sample was large and representative across states/territories, specialties and subspecialties, and the response fraction is similar to other surveys of busy health professionals.

Paediatricians called for rare disease resources to be made available via a single portal to simplify searching for information. The majority (82\%) wanted a directory of specialist referral services for rare diseases, despite only $21 \%$ being uncertain about referral pathways. Importantly, over $90 \%$ of paediatricians called for easily available printable fact sheets for patients and families, and a directory of family support groups to which families could be referred. Although Genetic Alliance Australia (formerly AGSA) provides counselling services and links to peer support groups for many genetic diseases, few paediatricians knew about this valuable service.

Paediatricians said they would be more likely to use online resources than printed materials or face-toface opportunities for education. Availability of online resources and awareness of these is essential to support 
their use in clinical practice, as needed. Female paediatricians and paediatricians aged $<50$ years would be more likely to use smartphone apps in clinical practice and these groups should be targeted if rare diseases apps were to be developed.

The APSU website houses information about many rare diseases, and provides links to well-respected resources such as OMIM and the Orphanet portal. Because APSU is well known to many Australian paediatricians and other child health clinicians, there is opportunity to build on existing infrastructure to develop a comprehensive information and educational portal with links to high-quality resources nationally and internationally. Furthermore, there is an opportunity to pool resources and to reach paediatricians in at least 11 countries through the International Network of Paediatric Surveillance Units. ${ }^{24}$

Our results support the need to raise awareness of rare disease resources while consolidating and disseminating via a single portal. To improve awareness, access to and actual use of resources in clinical practice, multiple strategies are needed to engage with paediatricians. Embedding specific teaching about rare diseases in undergraduate and postgraduate medical curricula would better equip future paediatricians to care for children with rare diseases. Paediatricians also need access to affordable genetic tests for their patients and to clinical geneticists' expertise to support meaningful clinical decisions.

\section{Author affiliations \\ ${ }^{1}$ Australian Paediatric Surveillance Unit, Kids Research Institute, Westmead, New South Wales, Australia \\ ${ }^{2}$ Discipline of Child and Adolescent Health, Sydney Medical School, The University of Sydney, Sydney, New South Wales, Australia \\ ${ }^{3}$ Telethon Kids Institute, The University of Western Australia, West Perth, Western Australia, Australia \\ ${ }^{4}$ Murdoch Children's Research Institute, University of Melbourne, Melbourne, Victoria, Australia \\ ${ }^{5}$ Clinical School, Sydney Children's Hospital Network, Sydney, New South Wales, Australia \\ ${ }^{6}$ Genetic Metabolic Disorders Research Unit, Western Sydney Genetics Program, the Children's Hospital at Westmead, Westmead, New South Wales, Australia ${ }^{7}$ Department of Paediatrics, Faculty of Medicine, Dentistry and Health Sciences, University of Melbourne, Victoria, Australia}

Acknowledgements The authors wish to thank all paediatricians who gave up their valuable time to complete our survey. They wish to thank Ms Amy Phu, from the APSU, The University of Sydney for data entry. They also thank representatives of the APSU Impacts of Rare Diseases Study Partners: Paul Russell, Nikki Sharp, Steve Waugh, Lynette Waugh and Patricia Van Leeuwen from the Steve Waugh Foundation; Dianne Petrie and Ayesha Wijesinghe from Genetic Alliance Australia (formerly Association of Genetic Support of Australasia); Evie Smith (the SMILE Foundation); Tam Johnston (Variety - the Children's Charity NSW), Philippa Ardlie, the Royal Australasian College of Physicians, for their insightful comments on the survey questions.

Contributors YZ: designed the study and analysis, interpreted data, and drafted the manuscript. $\mathrm{EE}, \mathrm{JC}, \mathrm{HL}$ and $\mathrm{MD}$ : contributed to study design and edited the manuscript. AG: finalised the survey design, undertook data analysis and wrote the results section. AP: digitised the survey, randomised the sample of respondents, oversaw the data collection, cleaned the data and prepared it for analysis. All authors: read and approved the final manuscript.
Funding This research was supported by an Australian Research Council Linkage Project grant scheme (project no. LP110200277). HL is supported by an NHMRC Senior Research Fellowship (no. 1117105) and EE is supported by an NHMRC Practitioner Fellowship (no. 1021480).

Disclaimer The views expressed herein are those of the authors and are not necessarily those of the Australian Research Council.

Competing interests None declared.

Ethics approval Sydney Children's Hospitals Network Human Research Ethics Committee.

Provenance and peer review Not commissioned; externally peer reviewed.

Open Access This is an Open Access article distributed in accordance with the Creative Commons Attribution Non Commercial (CC BY-NC 4.0) license, which permits others to distribute, remix, adapt, build upon this work non-commercially, and license their derivative works on different terms, provided the original work is properly cited and the use is non-commercial. See: http://creativecommons.org/ licenses/by-nc/4.0/

(C) Article author(s) (or their employer(s) unless otherwise stated in the text of the article) 2017. All rights reserved. No commercial use is permitted unless otherwise expressly granted.

\section{REFERENCES}

1. Zurynski Y, Frith $\mathrm{K}$, Leonard $\mathrm{H}$, et al. Rare childhood diseases: how should we respond? Arch Dis Child 2008;93:1071-4.

2. Elliott E, Zurynski Y. Rare diseases are a 'common' problem for clinicians. Aust Fam Physician 2015;44:630-3.

3. EURORDIS. The voice of 12,000 patients: experiences and expectations of rare disease patients on diagnosis and care in Europe. Boulogne-Billancourt, France: Eurordis, 2009:1-324.

4. Anderson M, Elliott EJ, Zurynski YA. Australian families living with rare disease: experiences of diagnosis, health services use and needs for psychosocial support. Orphanet J Rare Dis 2013;8:22.

5. Zurynski Y, Deverell M, Dalkeith T, et al. Australian children living with rare diseases: experiences of diagnosis and perceived consequences of diagnostic delays. Orphanet $J$ Rare Dis 2017:12:68.

6. Pelentsov LJ, Fielder AL, Laws TA, et al. The supportive care needs of parents with a child with a rare disease: results of an online survey. BMC Fam Pract 2016;17:88.

7. Baynam G, Pachter N, McKenzie F, et al. The rare and undiagnosed diseases diagnostic service - application of massively parallel sequencing in a state-wide clinical service. Orphanet $J$ Rare Dis 2016;11:77.

8. Walker CE, Mahede T, Davis G, et al. The collective impact of rare diseases in Western Australia: an estimate using a population-based cohort. Genet Med 2017;19:546-52.

9. Zurynski YA, Peadon E, Bower C, et al. Impacts of national surveillance for uncommon conditions in childhood. $J$ Paediatr Child Health 2007;43:724-31.

10. McCandless SE, Brunger JW, Cassidy SB. The burden of genetic disease on inpatient care in a children's hospital. Am J Hum Genet 2004;74:121-7.

11. Knight AW, Senior TP. The common problem of rare disease in general practice. Med J Aust 2006;185:82-3.

12. Phillips WR. Zebras on the commons: rare conditions in family practice. J Am Board Fam Pract 2004;17:283-6.

13. Australian Government Department of Health. National strategic framework for rural and remote health. $2011 \mathrm{http}: / / \mathrm{www}$.health. gov.au/internet/main/publishing.nsf/content/national-strategicframework-rural-remote-health (accessed 9 Jun 2017).

14. Shire. Rare disease impact report: insights from patients and the medical community. $2013 \mathrm{https} / /$ globalgenes.org/wp-content/ uploads/2013/04/ShireReport-1.pdf (accessed 9 June 2017).

15. Australian Bureau of Statistics. Australian standard geographical classification. 2011 http://www.abs.gov.au/websitedbs/D3310114 nsf/home/Australian+Standard+Geographical+Classification+\% 28ASGC\%29 (accessed 9 June 2017).

16. Harris PA, Taylor R, Thielke R, et al. Research electronic data capture (REDCap)-a metadata-driven methodology and workflow process for providing translational research informatics support. J Biomed Inform 2009;42:377-81.

17. He S, Zurynski YA, Elliott EJ. Evaluation of a national resource to identify and study rare diseases: the Australian Paediatric Surveillance Unit. J Paediatr Child Health 2009;45:498-504. 
18. He S, Zurynski YA, Elliott EJ. What do paediatricians think of the Australian Paediatric Surveillance Unit? J Paediatr Child Health 2010;46:412-8.

19. Mina K, Suthers G. The spectrum of genetic testing in Australia. Pathology 2013;45(Suppl 1):S3

20. Beale S, Sanderson D, Sanniti A, et al. A scoping study to explore the cost-effectiveness of next-generation sequencing compared with traditional genetic testing for the diagnosis of learning disabilities in children. Health Technol Assess 2015;19:1-90.

21. Ayme S, Rodwell C, eds. 2013 Report on the state of the art of rare disease activities in Europe. Brussels: European Union, 2013. http://
www.eucerd.eu/upload/file/Reports/2013ReportStateofArtRDAct ivities.pdf. (assessed 9 Jun 2017).

22. National Organization for Rare Disorders. NORD Physician Guides: rare disease resources for medical professionals. http:// nordphysicianguides.org/index-of-guides (assessed 9 Jun 2017).

23. NSW Government Health. Centre for genetics education. Resources for health professionals. http://www.genetics.edu.au/Professionals (assessed 9 Jun 2017).

24. Zurynski $Y$, Grenier D, Lynne R, eds. International network of paediatric surveillance units: 15 years of international research into rare childhood diseases. INoPSU, 2013. http://www.inopsu.com/Publications 